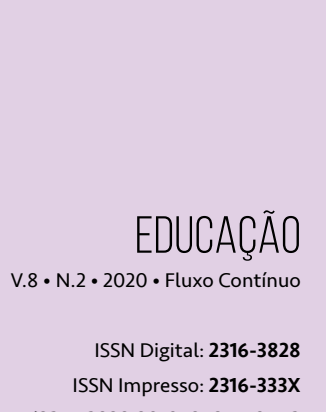

DOI: 10.17564/2316-3828.2019v8n2p158-173
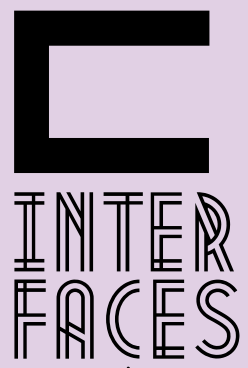

CIENTÍFICAS

\section{FORMAÇÃO INICIAL DE PROFESSORES DE CIÊNCIAS DA NATUREZA E CURRÍCULO: CONTRIBUIÇÕES DAS PESQUISAS BRASILEIRAS ENTRE 2012 E 2017}

INTIAL FORMATION OF NATURE SCIENCE TEACHERS AND CURRICULUMM: CONTRIBUTIONS FROM BRAZZLIAN RESEARCH BETWEEN 2012 AND 2017

FORMACIÓN INCIAL DE PROFESORES DE CIENCIAS DE LA NATURALEZA Y CURRÍCULO: CONTRIBUCIONES DE LAS INVESTIGACIONES BRASILEÑAS ENTRE २०१२ Y २०१७

\section{RESUMO}

Este estudo objetiva compreender a formação inicial de professores de Ciências da Natureza e sua relação com o currículo. Para isto, é apresentada uma revisão bibliográfica sistemática das pesquisas brasileiras entre os anos de 2012 e 2017, disponíveis nas bases de dados da SciELO e IBICT. Teses, dissertações e artigos foram utilizados para responder a seguinte situação-problema: quais pesquisas sobre a formação inicial de professores de Ciências da Natureza no Brasil, entre 2012 e 2017, impactam diretamente sobre os currículos? Os resultados indicam que os aspectos metodológicos e de estudo teórico sobre o modelo vigente de currículo na formação inicial são os estudos predominantes. As propostas metodológicas são aquelas que impactam diretamente sobre o currículo, uma vez que requerem a aplicação para posterior análise da viabilidade. As mudanças que ocorrem se efetivam, embora inclinadas a situações pontuais no currículo nos cursos de formação.

\section{PALAVRAS-CHAVE}

Formação Inicial de Professores. Ciências da Natureza. Currículo e Revisão Bibliográfica Sistemática. 


\section{RESUMEN}

El objetivo de este estudio es comprender la formación inicial de profesores de Ciencias de la Naturaleza y su relación con el currículo. Para esto, es presentada una revisión bibliográfica sistemática de las investigaciones brasileñas entre los años de 2012 y 2017, disponibles en las bases de datos de SciELO e IBICT. Tesis, disertaciones y artículos fueron utilizados para contestar la siguiente situación-problema: ¿cuáles investigaciones sobre la formación inicial de profesores de Ciencias de la Naturaleza en Brasil, entre 2012 y 2017, impactan directamente sobre los currículos? Los resultados indican que los aspectos metodológicos y de estudio teórico sobre el estándar vigente de currículo en la formación inicial son los estudios predominantes. Las propuestas metodológicas son aquellas que impactan directamente sobre el currículo, una vez que requieren la aplicación para un análisis posterior de su viabilidad. Los cambios que ocurren se efectivizan, aunque inclinados a situaciones puntuales en el currículo en los cursos de formación.

\section{PALABRAS-CLAVE}

Formación inicial de Profesores; Ciencias de la Naturaleza; Currículo y Revisión Bibliográfica Sistemática.

\section{ABSTRACT}

This study aims to understand the initial formation of Nature Science teachers and their relation to the curriculum. For that, a systematic literature review of the Brazilian researches between the years of 2012 and 2017, available in the databases of SciELO and IBICT, is presented. Thesis, dissertations and papers have been used in order to answer the following problem situation: what researches on the initial training of Nature Science teachers in Brazil between 2012 and 2017 has a direct impact on curricula? The results indicate that the methodological and theoretical aspects of the current curriculum model in initial training are the predominant studies. The methodological proposals are those that directly impact on the curriculum, once they require the application for later feasibility analysis. The changes that occur are effective, although are inclined to specific situations in the training courses curriculum.

\section{KEYWORDS}

Initial Teacher Training. Natural Sciences. Curriculum. Systematic Literature Review. 


\section{INTRODUÇ̧̃̃o}

Para compreender o campo das implicações envolvidas na formação inicial de professores no país e como o currículo possibilita a articulação entre o processo formativo e o conhecimento, primeiramente é necessário conhecer os estudos que se tem feito neste aspecto.

A formação para o exercício profissional de professor no Brasil, incorpora aspectos voltados para um exercício de demandas, além do processo de ensinar e aprender. Segundo as políticas educacionais para a formação de professores, o exercício profissional de professor requer estar adaptado ao contexto no qual se insere, seja este de certificação, de práticas, de currículos, de avaliações, dentre outros (BRASIL, 2001).

E para o caso da formação inicial de professores de Ciências da Natureza, devido aos novos paradigmas de ordem interdisciplinar da atividade científica e tecnológica, órgãos governamentais alertam para reformas dos currículos, tanto na educação básica como no ensino superior (SANTOS; VALEIRAS, 2014). A compreensão de currículo segundo Guimarães (2014), necessariamente implica a documentos oficiais, mas que envolve um processo simbiótico entre conteúdo e prática de ensino. As relações que compreendem o currículo composto de sabres recaem aos cursos de formação inicial de professores, nos quais não tem modificado, nem ao menos problematizado os saberes que o compõe (BARCELLOS, 2013).

Para tanto, com objetivo de compreender a formação inicial de professores de Ciências da Natureza e sua relação com o currículo nas pesquisas recentes, utilizou-se a base metodológica da revisão sistemática da literatura. Como os estudos sistemáticos de revisão refletem o mapeamento das fontes bibliográficas segundo Ramos e outros autores (2014), esta pesquisa esteve centrada em responder a seguinte situação-problema: quais pesquisas sobre a formação inicial de professores de Ciências da Natureza no Brasil, entre 2012 e 2017, impactam diretamente sobre os currículos? Nesse aspecto, é apresentada uma revisão da literatura neste artigo, no sentido de apresentar possíveis lacunas existentes da área, no sentido de contribuir para a demanda de novos estudos.

\section{METODOLOGIA}

Para o desenvolvimento deste trabalho optou-se pelo método da revisão bibliográfica sistemática. Segundo Kitchenham (2004), essa revisão é um meio de identificar, avaliar e interpretar as pesquisas da área ou fenômenos de interesse do investigador. Para a área da Educação, a revisão sistemática ainda é pouco adotada, mas se utilizada, permite o aprofundamento dos procedimentos de investigação (RAMOS et al., 2014). Nesse aspecto, a revisão bibliográfica sistemática realizada, compreendeu de pesquisas nas bases de dados disponíveis da biblioteca eletrônica da Scientific Electronic Library Online (SciELO) - com artigos e da biblioteca do Instituto Brasileiro de Informação em Ciência e Tecnologia (IBICT) - com dissertações e teses. 
Para rastrear as publicações, dentre os operadores lógicos and, or e and not empregou-se aquele que mais satisfez a intenção deste estudo nas palavras-chave e na combinação dos descritores. Primeiramente, foram definidas as palavras-chave: (Formação de Professores) and (Currículo) no intuito de abranger um número expressivo de publicações, que de acordo com Ramos (et al, 2014), torna possível efetuar as devidas exclusões até se chegar a uma quantidade de trabalhos entendidos como pertinentes ao foco da pesquisa.

E, na sequência, ocorreu a definição das combinações: (Formação de Professores de Biologia) and (Currículo); (Formação de Professores de Ciências da Natureza) and (Currículo); (Formação de Professores de Física) and (Currículo); e (Formação de Professores de Química) and (Currículo). A combinação de tais palavras ocorreu pelo fato da área das Ciências da Natureza incorporar, segundo as Orientações Curriculares Nacionais (OCN), as disciplinas de Biologia, Física e Química, devido a relação de conhecimento entre elas (BRASIL, 2006).

Definidas as palavras-chave e as combinações apropriadas para o foco desta pesquisa, adotou-se os seguintes critérios de inclusão para realizar a revisão sistemática na SciELO e na IBICT: a) trabalhos desenvolvidos no Brasil e no idioma português; b) trabalhos publicados entre os anos de 2012 a 2017; e c) todas as publicações que contemplem ao menos um dos seguintes aspectos: formação inicial de professores de Ciências da Natureza, Biologia, Física ou Química; currículo ou abordagem curricular.

Após a busca, as publicações que estavam catalogadas nas bases e que não contemplavam exatamente as palavras-chave e as combinações atribuídas, os resumos delas foram lidos na íntegra para se adotar então os critérios de inclusão. Já os critérios de exclusão empregados na busca de publicações, em ambas as bases de dados envolveram: os estudos direcionados a formação continuada de professores tanto de Ciências da Natureza, quanto das disciplinas específicas que abrangem a área; estudos duplicados; não-citáveis; de arquivos não disponíveis nas bibliotecas; e estudos de revisão.

Para a operacionalização da revisão sistemática deste trabalho, optou-se por utilizar o software Mendeley como ferramenta para o gerenciamento das referências. Intencionalmente, esta pesquisa se restringiu ao levantamento dos dados de interesse no sentido de compreender como o currículo está implicado na formação inicial docente, pelo fato do país estar passando por um momento histórico de modificações no campo curricular da educação básica (BRASIL, 2016).

\subsection{EXTRAÇ̃̃O DOS DADOS}

Na Tabela 1 é apresentada quantitativamente o número de publicações de acordo com os critérios de inclusão e exclusão adotados para os descritores empregados. 
Tabela 1 - Número de publicações de acordo com os critérios de inclusão e exclusão adotados

\begin{tabular}{|c|c|c|c|c|c|c|}
\hline Descritures & $\begin{array}{c}\text { ScitLL } \\
\text { Número total } \\
\text { (Artigos) }\end{array}$ & $\begin{array}{l}\text { IBICT Número total } \\
\text { (Teses e Dissertaçōes) }\end{array}$ & sa & $\begin{array}{l}\text { Critérios de } \\
\text { Inclusão } \\
\text { b }\end{array}$ & & $\begin{array}{l}\text { Critérios de } \\
\text { Exclusão }\end{array}$ \\
\hline $\begin{array}{l}\text { Formaçio de Professores } \\
\text { and Curriculo }\end{array}$ & 238 & 2174 & & & & \\
\hline $\begin{array}{l}\text { Formação de Professores } \\
\text { and Curriculo }\end{array}$ & 87 & 1081 & $\mathrm{x}$ & $\mathrm{x}$ & & \\
\hline $\begin{array}{l}\text { Formação de Professores } \\
\text { de Ciéncias da Natureza } \\
\text { and Curriculo }\end{array}$ & 1 & 87 & $\mathrm{x}$ & $\mathrm{x}$ & & \\
\hline $\begin{array}{l}\text { Formação de Profersores } \\
\text { de Física and Curriculo }\end{array}$ & 11 & 159 & $\mathrm{x}$ & $x$ & & \\
\hline $\begin{array}{l}\text { Formação de Professores } \\
\text { de Química and Curriculo }\end{array}$ & 5 & $5 !$ & $x$ & $\mathrm{x}$ & & \\
\hline $\begin{array}{l}\text { Formacia de Professores } \\
\text { de Biologia and Currículo }\end{array}$ & 3 & 48 & $\mathrm{x}$ & $\mathrm{x}$ & & \\
\hline $\begin{array}{l}\text { Formaciòo de Professores } \\
\text { de Ciências da Natureza } \\
\text { and Curriculo }\end{array}$ & 1 & 12 & $\mathrm{x}$ & $\mathrm{x}$ & $\mathrm{x}$ & $\mathrm{x}$ \\
\hline $\begin{array}{l}\text { Formação de Professores } \\
\text { de Fisica and Curriculo }\end{array}$ & 0 & 3 & $\mathrm{x}$ & $\mathrm{x}$ & $\mathrm{x}$ & $\mathrm{x}$ \\
\hline $\begin{array}{l}\text { Formação de Professores } \\
\text { de Química and Curriculo }\end{array}$ & 3 & 4 & $\mathrm{x}$ & $\mathrm{x}$ & $\mathrm{x}$ & $\mathrm{x}$ \\
\hline $\begin{array}{l}\text { Formacăa de Professores } \\
\text { de Biologia aud Curriculo }\end{array}$ & 1 & 2 & $\mathrm{X}$ & $\mathrm{x}$ & $x$ & $x$ \\
\hline
\end{tabular}

Fonte: Tabela elaborada pelos autores

As tabelas na sequência apresentam as 26 publicações eleitas para cada uma das áreas de formação inicial de professores.

Tabela 2 - Publicações eleitas na área da Formação inicial de professores de Física e Currículo

\begin{tabular}{|c|c|c|c|}
\hline Autor & Título & Artig0 & Tese \\
\hline $\begin{array}{l}\text { BARCELLOS, } \\
\text { M. E. }\end{array}$ & $\begin{array}{l}\text { Conhecimento e currículo: } \\
\text { problematizando a licenciatura em fisica }\end{array}$ & & $\mathrm{X}$ \\
\hline $\begin{array}{l}\text { GUIMARÃES, } \\
\text { Y A F }\end{array}$ & $\begin{array}{l}\text { Identidade Curricular na Formação } \\
\text { Inicial de Professores de Física. }\end{array}$ & & $\mathrm{X}$ \\
\hline $\begin{array}{l}\text { RODRIGUES, } \\
\text { A. M }\end{array}$ & $\begin{array}{l}\text { Movimento e Contradição: A disciplina } \\
\text { de práticas em ensino de física e a } \\
\text { formação inicial de professores de fisica } \\
\text { sob uma perspectiva histórico-cultural. }\end{array}$ & & $X$ \\
\hline
\end{tabular}

Fonte: Tabela elaborada pelos autores

$\cdot 162 \cdot$ 
Tabela 3 - Publicações eleitas na área da Formação inicial de professores de Química e Currículo

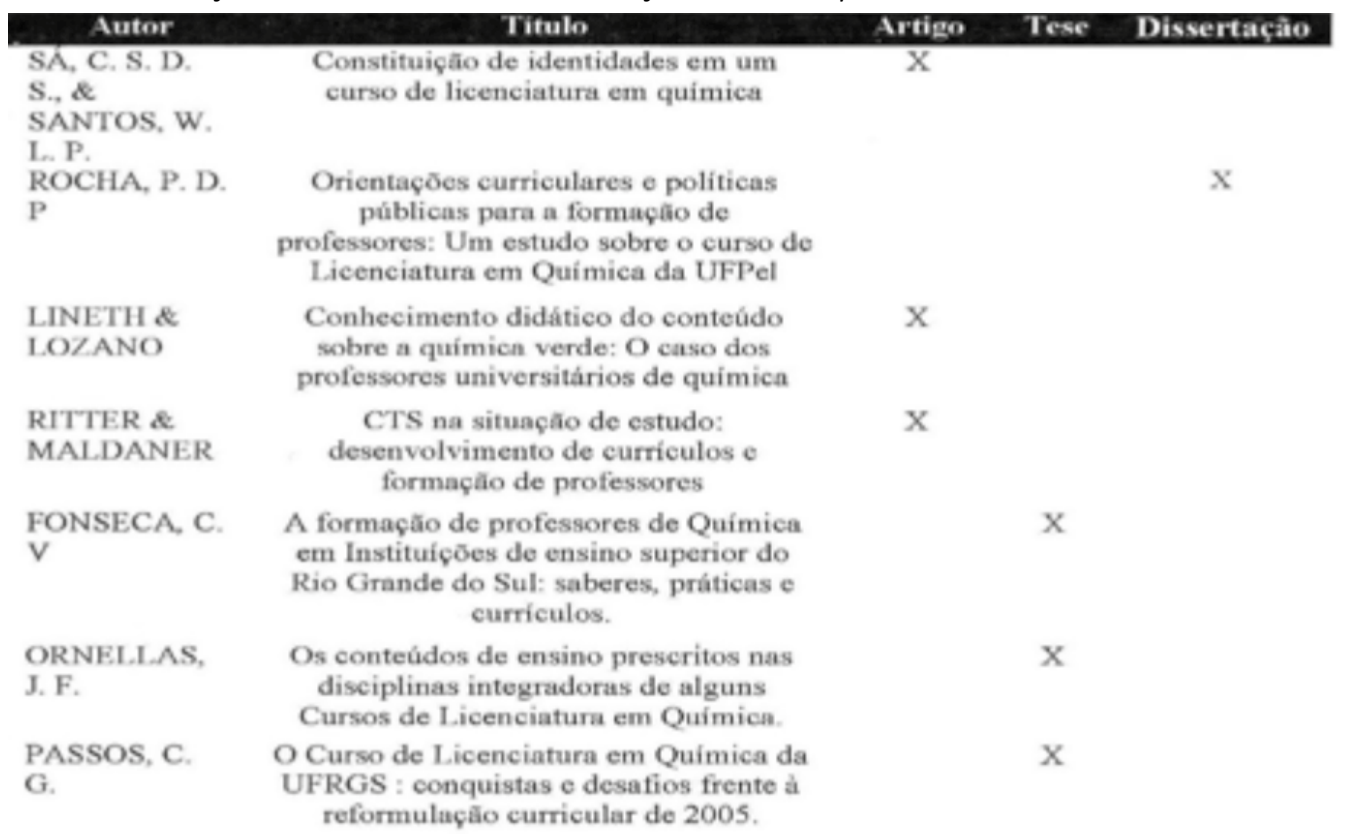

Fonte: : Tabela elaborada pelos autores

Tabela 4 - Publicações eleitas na área da Formação inicial de professores de Biologia e Currículo

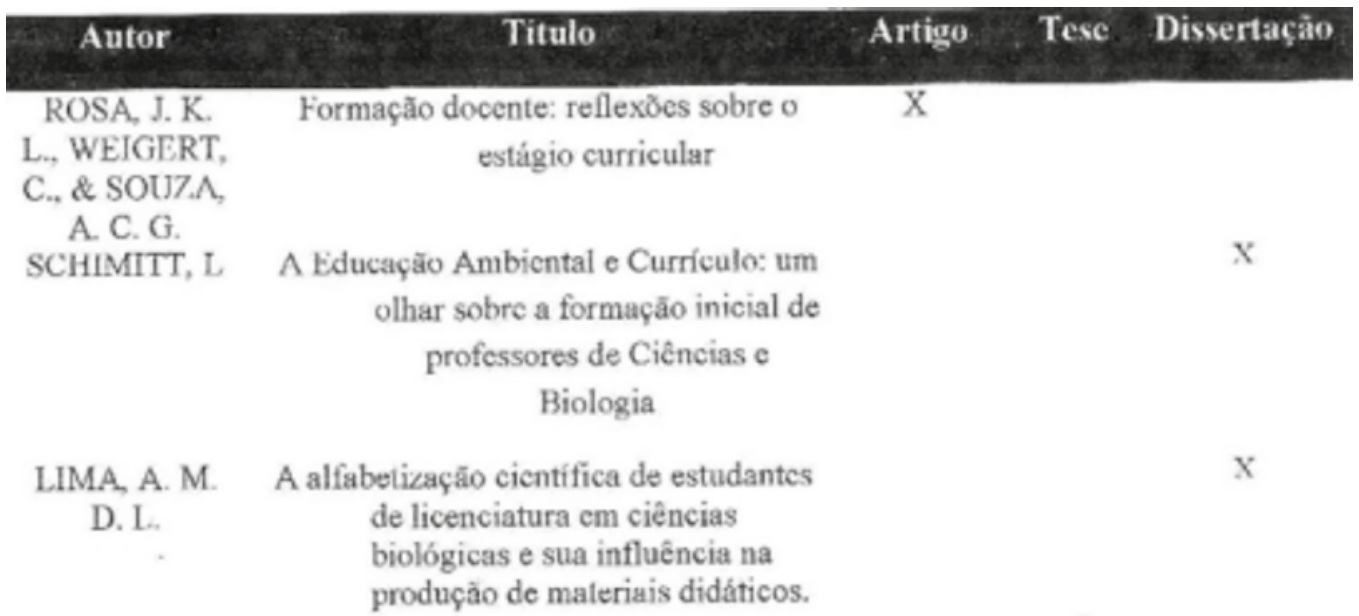

Fonte: : Tabela elaborada pelos autores 
Tabela 5 - Publicações eleitas na área da Formação inicial de Professores de Ciências da Natureza e Currículo

\begin{tabular}{|c|c|c|c|c|}
\hline Auter & Titulo & Aratgo & Tese & Disuertaciao \\
\hline $\begin{array}{l}\text { SANTOS, C. A., \& } \\
\text { VALEIRAS, N. }\end{array}$ & $\begin{array}{l}\text { Curriculo interdisciplinar para licenciatura cm Ciếncias } \\
\qquad \text { da Nutureza. }\end{array}$ & $\mathrm{X}$ & & \\
\hline $\begin{array}{c}\text { COL_AGANDF, E. } \\
\text { A }\end{array}$ & $\begin{array}{l}\text { A natureza da ciência e a interpreiaçlio de situaçðes } \\
\text { cientificas - um estudo com professores de ciências em } \\
\text { formaçso }\end{array}$ & & $\mathrm{x}$ & \\
\hline$\underset{\text { MRETT AS, T. G. R. }}{\text { F }}$ & $\begin{array}{l}\text { Escolha de tamas relevantes para o cumiculo de Ciências } \\
\text { a partir de fotografias feitas por professorcs cm formaçà }\end{array}$ & & & $\mathrm{x}$ \\
\hline LAOO, A O & 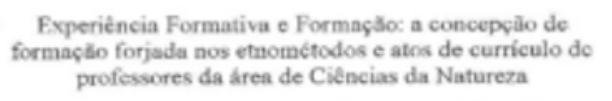 & & & $x^{*}$ \\
\hline PTREIRA, F, A & $\begin{array}{l}\text { A Integração Curricular da Educayão Ambiental na } \\
\text { Formaşâo laicial de Professores: teccndo fios e revelando } \\
\text { desafios da pesquisa académica brasileira. }\end{array}$ & & $\mathrm{X}$ & \\
\hline SOUZA, E. P. L. & $\begin{array}{l}\text { Estudos sobre a formaçăo de professores de ciéncias no } \\
\text { contexto da lei } 10.639 .03\end{array}$ & & & $\mathrm{x}$ \\
\hline VERDUM, P. L & $\begin{array}{l}\text { Formaça inicial de professores pura a educaçăo básica, } \\
\text { no contexto dos II's: propondo indicadores de qualidade, } \\
\text { a partir de um estudo de caso no IFRS }\end{array}$ & & $\mathrm{X}$ & \\
\hline ARANTES, F, J. F. & $\begin{array}{l}\text { Formaçăo de professores nas licenciaturas do Instituto } \\
\text { Federal Goinano }\end{array}$ & & & $\mathrm{X}$ \\
\hline CANZLANI, T.M & $\begin{array}{l}\text { Analise da perspectiva iategradora do curriculo } \\
\text { flexibilizado na Licenciatura em Ciencias da } \\
\text { Universidade Federal do Paraná - Setor I.itoral }\end{array}$ & & $\mathrm{X}$ & \\
\hline Joticosk1, E & $\begin{array}{l}\text { Desenvolvimento profissional e inovaçâo curricular na } \\
\text { T.icenciatura em Ciencias da UFPR Litoral. }\end{array}$ & & $\mathrm{X}$ & \\
\hline FRANCO, E. K & $\begin{array}{l}\text { Movimentos de mudanç: um cstudo de caso sobre } \\
\text { inovaça curricular em cursos de Licenciatura da } \\
\text { UFPR Litoral. }\end{array}$ & & $\mathrm{X}$ & \\
\hline FEISTEL, R. A. 13. & $\begin{array}{l}\text { Contribuigoes da perspectiva freiriana de cducaçso para a } \\
\text { interdisciplinaridade na formaçào inicial de professores } \\
\text { de ciências }\end{array}$ & & $\mathrm{X}$ & \\
\hline VIANE, G. M & $\begin{array}{c}\text { Construç̄es de Relaçōes Teoria-Prática Na Formaçăo De } \\
\text { Professores De Ciências E Biologia. }\end{array}$ & & $\mathrm{x}$ & \\
\hline
\end{tabular}

Fonte: : Tabela elaborada pelos autores

\section{DISCUSSÕES SOBRE O CURRÍCULO E A FORMAÇÃO INICIAL DE CIÊNCIAS DA NATUREZA}

A área da formação de professores dentro das pesquisas em Educação e sua ligação aos saberes do currículo, revela o emergir das interfaces entre o processo formativo da licenciatura e os conhecimentos agregados para este fim. Estudos relativos à formação inicial de professores apresentam críticas diretas à fragmentação dos saberes do currículo e a dicotomia teoria-prática (BARCELLOS, 2013; SÁ; SANTOS, 2017; KELLE et al., 2012; CANZIANI, 2015; ROSA et al., 2012; VERDUM, 2015; LIMA, 2016). Nesse aspecto, pergunta-se: como trabalhar de maneira associada os saberes que compõe o currículo, para formar professores conectados com a realidade escolar? Há um caminho ou uma estratégia que garanta a conecção dos saberes do currículo à prática docente? 
Para um curso de formação inicial de professores é fato que este possui um currículo. Também é fato que este currículo foi elaborado por um corpo docente com suas especificidades, além das normativas impostas pelas políticas públicas da educação básica e da formação de professores no país. A compreensão de tais afirmativas é apresentada neste trabalho pelas contribuições das pesquisas analisadas para cada uma das seguintes categorias: Formação inicial de professores de Física; Formação inicial de professores de Química; Formação inicial de professores de Biologia; e Formação inicial de professores de Ciências da Natureza.

\subsection{CURRÍCULO NA FORMACG̃̃O INICIAL DE PROFESSORES DE FÍSICA}

Os estudos direcionados ao currículo do processo formativo do professor de Física, se fizeram presentes na disciplina de Práticas em Ensino de Física, na concepção do conhecimento da área Ensino de Física e na cultura como princípio que caracteriza o currículo na formação inicial (RODRIGUES, 2013; GUIMARÃES, 2014; BARCELLOS, 2013).

As publicações na área da Física corresponderam a 11,5\% do total. A formação docente como um campo de reprodução e de transformação social, são exemplos de singularidades ausentes no currículo segundo Rodrigues (2013). Para isto, buscou caracterizar os materiais elaborados para a disciplina de Práticas de Ensino de Física, estreitando as relações entre Universidade-Escola. Estreitar as relações entre os licenciandos e a realidade escolar, permite que eles passem a fazer parte daquela realidade e nela provoque problematizações, diminuindo as possíveis fragilidades do currículo.

Contudo, um currículo que incorpore saberes na área do Ensino, no sentido de promover a construção de uma consciência crítica-reflexiva deste licenciando, permitirá que durante seu processo de formação no âmbito Universidade-Escola detecte, construa e aponte condições de mudança. Como Rodrigues (2013) salientou no seu trabalho, os licenciandos ridicularizam disciplinas pedagógicas, acreditando não ocuparem espaço na prática de sala de aula.

Um currículo disposto de saberes da Física agregados a saberes da Pedagogia, conotam pesquisas para um currículo que não trabalhe tais saberes de maneira independente, para serem aplicados posteriormente na escola em conjunto. Nesse sentido, Barcellos (2013) constrói em sua pesquisa um aporte teórico da necessidade de entender as duas áreas do conhecimento, a área dos sabres da Física e dos saberes da Pedagogia como apenas um corpo de conhecimentos.

As concepções de educação e de conhecimento que vem crescendo na comunidade cientifica da área educacional, ainda estão distantes dos currículos da formação inicial de professores de Física. 0 Ensino de Física como área, está no sentido de agregar saberes e conhecimentos da prática pedagógica e da teoria da Física como um corpo de conhecimentos, incorporados ao currículo para a formação inicial de professores de Física (BARCELLOS, 2013).

O currículo para a formação inicial de professores, embora carregado de escolhas políticas/éticas/ sociais/tradicionais nas quais as pesquisas desta revisão apresentam, é notório como tais escolhas decidem o cenário da sociedade. Discutir a Identidade Curricular de um curso de formação inicial de professores de Física, segundo Guimarães (2014), abrange o fato de compreende o lugar da Cultura dentro das Universidades e os objetivos formativos para o professor. A Identidade Curricular é, segun- 
do a autora, fundamental para se conhecer um curso de formação inicial, suas características, jogos de poder, contexto histórico, social etc., mediadas pelo currículo.

\subsection{CURRÍCULO NA FORMAÇÃO INICIAL DE PROFESSORES DE QUÍMICA}

As relações com o currículo na formação inicial de professores de Química estiveram presentes em $27 \%$ das publicações analisadas exclusivas para esta categoria.

Os estudos de Lineth e Lozano (2015), se inserem na relação de ambientalizar um currículo de Química na formação inicial de professores. Afirmam que se deve incorporar ao currículo os problemas ambientais, para que os professores formadores estimulem os licenciandos durante o processo formativo a lidar com questões complexas em diversas perspectivas como na política, tecnologia, na cultura, dentre outras. E o trabalho de Passos (2012), esteve centrado em analisar os modelos didáticos adotados e as concepções epistemológicas após a reformulação curricular de um curso de formação inicial de professores de Química. Embora novas disciplinas de práticas de ensino se fizessem presentes no currículo, ainda predominava a dicotomia teoria-prática devido as relações conturbadas entre a Universidade e as Escolas.

Quando se trata de currículo e formação de professores, se aponta para fundamentos constituídos por teorias e práticas que se consolidam como saberes necessários para a formação docente. Caso esses saberes organizados teoricamente não estejam em sintonia com a prática docente durante o processo formativo, o currículo acaba se resumindo em apenas um conjunto de conhecimentos organizados.

Os estudos de Passos (2012) estavam direcionados aos saberes da Química aplicados à Educação, inseridos nas disciplinas articuladoras, assim como os estudos de Ornellas (2016). A autora apontou que as ementas dos currículos dessas disciplinas não representam necessariamente as aulas que ocorriam no curso para a formação dos professores e que novos estudos seriam necessários para afirmar com precisão se estão direcioandos a própria formação academica do professor formador. Nesse aspecto, os autores Sá e Santos (2017) direcionaram seus estudos a reformulação curricular, pelo fato dos professores formadores passarem a se especializar na área da Educação e do Ensino de Química.

A formação com o currículo linear (modelo $3+1$ ) e a formação com o currículo com identidade específica para a licenciatura, chegaram ao fator comum: os licenciados dispensavam à docência como profissão. Nesse aspecto, Ritter e Maldaner (2014) apontam para a formação do professor como pesquisador, na qual ele aprenda durante a sua formação a construir um currículo da Química para o Ensino Médio ao invés de apenas aplicá-lo.

Diante de estudos em perspectivas diferenciadas, é possível detectar que uma especialização na área, não é resultado para ações transformadoras dos professores formadores em relação ao currículo na formação inicial. E também não se pode generalizar de que toda formação na área do Ensino/ Educação implica em resultados satisfatórios nesse aspecto. 0 âmbito da formação docente envolve questões muito mais amplas, direcionadas àquelas que partem da questão da consciência que se têm e, da que se exerce como educador/professor.

Ainda, Rocha (2014) analisa em seus estudos como o Exame Nacional de Desempenho de Estudantes (ENADE) está desarticulado do Ensino da Química. 0 exame acaba priorizando questões em 
seus testes específicos à Química voltada para a pesquisa e a Pedagogia, ao invés de questões voltadas para atuação da prática docente no Ensino Médio. Fonseca (2014) em suas pesquisas demonstrou que o ENADE caminha contra a uma (nova) racionalidade, aquela direcionada ao Ensino da Química.

\subsection{CURRÍCULO NA FORMAÇÃO INICIAL DE PROFESSORES DE BIOLOGIA}

A Biologia como área para a formação inicial de Professores, apresentou um total de $11,5 \%$ das publicações nesta revisão bibliográfica. Assim como as propostas, estratégias e os estudos direcionados às Ciências da Natureza, a Biologia também apresentou publicações nos últimos cinco anos sobre a formação inicial de professores e suas relações ao currículo.

O trabalho de Schimitt (2016) envolveu a aplicação de uma estratégia metodológica para a formação inicial de professores, revelando como resultados a preocupação pelo fato do currículo ser compreendido pelos envolvidos por um caráter neutro, o que despolitiza o processo de formação inicial e acarreta em práticas docentes desarticuladas aos saberes do currículo. Lima (2016) incorpora como sugestão ao currículo de um curso de Biologia, uma Alfabetização Científica, indo ao encontro dos estudos de Santos \& Valeira (2014).

Lima detectou na construção de material didático pelos licenciandos de Biologia, a familiaridade dos mesmos no trato de questões envolvidas sobre o conteúdo da Ciência, o que não ocorreu com a natureza do conhecimento e seus impactos sobre a tecnologia. Segundo o autor, a Alfabetização Científica pode viabilizar um ensino de ciências mais comprometido, do que um ensino essencialmente conceitual.

Dos saberes que compõem o currículo para a formação inicial, a pesquisa de Rosa (et al, 2012) esteve direcionada a disciplina de Estágio Curricular Supervisionado, na qual prevaleceu a dicotomia teoria-prática como reflexo do modelo de formação “ $3+1$ ”. A disciplina de estágio curricular assim como as demais disciplinas do currículo de um curso de licenciatura, devem estar inclinadas para promover à docência, ao invés de uma área específica incorporar disciplinas pedagógicas como adendo, no intuito de caracterizar o curso de formação para a docência.

Pela revisão sistemática realizada foi possível detectar a carência de pesquisas específicas à Biologia como área. As propostas analisadas se remetem a um número superior de publicações que contribuem com pesquisas às Ciências do Ensino Fundamental, do que propriamente para a Biologia como disciplina do Ensino Médio. Não está presente neste estudo atribuir argumentos plausíveis como resposta a este fato detectado. Mas é possível atribuir como hipótese a própria posição que a disciplina de Ciências ocupa nos currículos escolares em detrimento à disciplina de Biologia.

É importante salientar, neste momento, que tal hipótese referida não se aplica às pesquisas para a área da Química e da Física, nas quais as atribuições de ambas estão presentes como disciplinas apenas no Ensino Médio e, em raros casos, no $9^{\circ}$ ano do Ensino Fundamental.

\subsection{FORMAC̄̃̃ INICIAL DE PROFESSORES DE CIÊNCIAS DA NATUREZA}

O campo da formação inicial de professores de Ciências da Natureza no Brasil apresentou o maior número de pesquisas relacionadas ao currículo nos últimos cinco anos. A revisão sistemática realiza- 
da nesta área mostrou um total de $50 \%$ das pesquisas realizadas, conectando o processo formativo do professor ao currículo.

As Ciências da Natureza como área que abrange as disciplinas de Biologia, Física e Química, apresentou pesquisas curriculares dentro de duas abordagens específicas. Uma direcionada aos estudos do currículo na formação inicial nos cursos de Licenciatura em Biologia (VIANE, 2014; PEREIRA, 2014) e outra com viés interdisciplinar em cursos de Licenciatura em Ciências/Ciências e Matemática/Ciências Naturais/Ciências da Natureza (SOUZA, 2014; ARANTES, 2013; SANTOS; VALEIRAS, 2014; CANZIANI, 2015; COLAGRANDE, 2016; FRANCO, 2014; VERDUM, 2015; LAGO, 2012; FEISTEL, 2012; FRANCO, 2014; FREITAS, 2013; JOUCOSKI, 2015).

É presente, nas publicações analisadas, uma convergência dos autores quanto ao lapso existente entre os cursos de formação inicial de professores de Ciências da Natureza e as políticas públicas da Educação (LAGO, 2012; CANZIANI, 2015; VERDUM, 2015; PEREIRA, 2014; FEISTEL, 2012; SANTOS; VALEIRAS, 2014). As políticas recentes de formulação curricular para a educação básica no país, com a Base Nacional Comum Curricular (BNCC), ainda requer debates e contribuições de especialistas, tanto para o documento, como para o que seja o curso de formação de professores na área das Ciências da Natureza. Mesmo que as políticas apresentem em seus prescritos incentivos a uma formação docente generalista, no qual o professor tenha condições de representar uma área do conhecimento, as políticas deixam de estabelecer critérios que pautem e caracterizem esta iniciativa no processo formativo.

Desse modo, segundo a autora Pereira (2014), o desafio quando se trata de currículo na formação inicial de professores de Ciências da Natureza é de colocar em prática ações que possibilitem a integração dos conceitos presentes no currículo, como para o caso da Educação Ambiental. Na relação teoria-prática como foco de pesquisa, a autora Viane (2014) apresentou uma proposta de integração curricular sem modificações ou reestruturações na matriz curricular.

0 trabalho envolveu a utilização de espaços físicos do próprio curso como meio de integrar as disciplinas do currículo, trazendo como resultados a maior interação dos licenciandos entre a Ciência (Ensino Fundamental) e a Biologia (Ensino Médio) direcionada à prática de ensino (VIANE, 2014). Todo e qualquer espaço físico dentro de centros de formação de professores, deveriam receber uma atenção em especial, no sentido de contribuir de maneira direta no processo formativo, quer estejam ligados a Ciência, ou a Educação, ou ao Ensino.

No sentido de romper com a fragmentação do currículo na formação inicial, Feistel (2012) baseada na pedagogia de Paulo Freire, apresenta uma proposta de currículo interdisciplinar para a formação inicial de professores por meio da pedagogia de projetos. Colhendo como resultados fatores limites à implementação dela, a autora enfatiza a ausência de respaldo das políticas públicas; a própria formação dos professores formadores; a compreensão do que significa/envolve a interdisciplinaridade, dentre outros.

A promoção da articulação da matriz curricular, dentro de uma perspectiva interdisciplinar por temas, segundo a proposta desenvolvida de currículo por Santos \& Valeiras (2014), permite o trabalho articulado dos professores formadores em cursos de formação inicial generalista, promovendo que os docentes tenham além da competência na disciplina de Ciências para o Ensino Fundamental, também para Biologia, Física e Química no Ensino Médio. 
Já Freitas (2013), preocupa-se com o processo formativo do professor atrelado ao currículo como um resultado à educação básica. Utiliza para isto uma abordagem metodológica pelo uso de fotografias. $O$ interesse da autora não está no currículo estruturante, mas sim na maneira em que o professor em formação passa a organizar a matriz curricular, usando para isto tal objeto comum a todos os envolvidos. Nesse contexto, o autor Lago (2012) apresenta uma estratégia de formação docente por 'circunstâncias do contexto educativo', apresentando o que chama de "modos de fazer" e "modos de usar" saberes e conhecimentos concebidos como atos de currículo e/ou etnométodos curriculares.

Os estudos de Arantes (2013) revelam que a construção de currículos pelos docentes, dentro de uma matriz com o modelo $3+1$ (matriz do curso de bacharelado acrescentada as disciplinas pedagógicas no último ano para o curso de licenciatura) geralmente ocorre pela ausência de formação dos currículos na área de ensino. Apresenta a discordância que ocorre entre os currículos elaborados que priorizam uma matriz curricular com disciplinas específicas, em detrimento a disciplinas de formação docente, mostrando que isso se deve a uma relação "desconexa" entre a demanda de mercado e a demanda de abertura de cursos em licenciatura.

Tal situação vai de encontro ao trabalho desenvolvido por Verdum (2015). De maneira geral toda organização sistemática que compõe os cursos de formação docente, agregam interesses, negociações, aspectos políticos, dentre outros. Joucoski (2015) afirma que as instâncias de poder também se inserem sobre os currículos nas Universidades. Contudo, o conjunto de características socialmente construídas não deve responder a um currículo neutro para a formação inicial de professores.

Para propostas de currículos diferenciados e flexíveis para a formação inicial de professores de Ciências da Natureza, Canziani (2015) apresenta em seus estudos um panorama das políticas públicas, em especial entre os anos de 2008 a 2015. Salienta que para este intervalo de tempo, predominam prescrições na inclusão de currículos flexibilizados para a formação inicial de professores generalistas, de maneira a suprir a falta de professores em áreas como Química e Física, embora "[...] o governo se abstém de discutir com mais profundidade sobre o trabalho integrado por áreas do saber" (CANZIANI, 2015, p. 198).

Diante do cenário obscuro para a construção de currículos que venham atender novas demandas das políticas públicas na educação básica brasileira, as publicações pesquisadas revelam docentes engajados quanto ao papel dos currículos, como resposta a formação docente na área das Ciências da Natureza propondo maneiras/métodos/práticas para se efetivar um currículo conectado com as demandas da sociedade. 0 processo formativo do professor de maneira a agregar disciplinas da área das Ciências da Natureza em dinâmicas/metodologias curriculares, surge da necessidade de procedimentos que pensados apenas no sentido disciplinar, não faz sentido, mas que passa a fazer quando o campo do conhecimento se apresenta com questões de ordem complexa.

\section{CONCLUSÕES}

É importante salientar que a elaboração deste estado do conhecimento na formação inicial de professores de Ciência da Natureza e sua relação com o currículo é um recorte de 26 publicações 
qualificadas e compreendidas por um período delimitado. Por ventura, novos estudos podem incorporar alguns novos resultados a esta pesquisa, mas que não retira sua relevância quanto à rigorosidade dos dados aqui apresentados.

As discussões referentes ao fosso existente entre a formação inicial de professores no país e a articulação dos saberes que incorporam o currículo, requer primeiramente inteirar-se das pesquisas, deixando de lado o fato de atribuir mérito a uma em detrimento a outras. Aspectos metodológicos ou estudos com análise crítica sobre o modelo vigente de currículo, são os predominantes nos últimos cinco anos na área da formação inicial de professores de Ciências da Natureza. Priorizar estudos de currículo direcionados ao Ensino como área específica na formação inicial, é um caminho de possibilidades. A formação de professores necessita estar conectada ao currículo em uma posição temporal, com saberes organizados de maneira ativa, campo este com possibilidades de novos estudos.

Ainda que os estudos da formação inicial de professores sobre os currículos incorporem aspectos relevantes com estudos/propostas para mudanças, não se observou nas pesquisas da área, impactos para modificar e/ou reestruturar as políticas públicas que balizam a formação de professores no Brasil, caminho este que poderia trazer as demandas necessárias para a formação docente contemporânea.

\section{REFERÊNCIAS}

ARANTES, F. J. F. Formação de professores nas licenciaturas do Instituto Federal Goiano: políticas, currículos e docentes. 2013. 141f. Dissertação (Mestrado em Educação) - Universidade Federal de Goiás, Catalão. 2013.

BARCELLOS, M. E. Conhecimento e currículo: problematizando a licenciatura em física. 2013. 247f. Tese (Doutorado em Ensino de Ciências) - Universidade de São Paulo, São Paulo. 2013.

\section{CANZIANI, T. M. Análise da perspectiva integrada do currículo flexibilizado na Licenciatura} em Ciências da Universidade Federal do Paraná - Setor Litoral. 2015. 250f. Tese (Doutorado em Educação) - Universidade de São Paulo, São Paulo. 2015.

\section{FEISTEL, R. A. B. Contribuições da perspectiva freiriana de educação para a interdisciplinaridade} na formação inicial de professores de ciências. 2012. 372f. Tese (Doutorado em Educação Científica e Tecnológica) - Universidade Federal de Santa Catarina, Florianópolis, 2012.

FONSECA, C. V. A formação de professores de Química em Instituições de ensino superior do Rio Grande do Sul: saberes, práticas e currículos. 2014. 325 f. Tese (Doutorado em Educação Científica e Tecnológica) - Universidade Federal de Santa Catarina, Florianópolis, 2014. 
FREITAS, T. G. R. M. Escolha de temas relevantes para o currículo de Ciências a partir de fotografias feitas por professores em formação. 2013. 111f. Dissertação (Mestrado em Educação) Universidade Federal de Minas Gerais, Belo Horizonte, 2013.

GUIMARÃES, Y. A. F. Identidade curricular na formação inicial de professores de física. 2014. 511f. Tese (Doutorado em Ensino de Ciência) - Universidade de São Paulo, São Paulo, 2014.

JOUCOSKI, E. Desenvolvimento profissional e inovação curricular na Licenciatura em Ciências da UFPR Litoral. 2015. 348f. Tese (Doutorado em Ensino de Ciências) - Universidade de São Paulo, São Paulo, 2015.

LAGO, A. O. Experiência formativa e formação: a concepção de formação forjada nos etnométodos e atos de currículo de professores da área de Ciências da Natureza. 2012. 159f. Dissertação (Mestrado em Educação) - Universidade Federal da Bahia, Salvador, 2012.

LIMA, A. M. D. L. A alfabetização científica de estudantes de licenciatura em ciências biológicas e sua influência na produção de materiais didáticos. 2016. 83f. Dissertação (Mestrado em Educação em Ciências) - Universidade Federal do Rio Grande do Sul, Porto Alegre, 2016.

LOZANO, P. D. L. Conhecimento didático do conteúdo sobre a química verde: o caso dos professores universitários de química. Revista de la Facultad de Ciencia y Tecnología - Tecné, Episteme y Didaxis, n. 38, p. 167-182, 2015.

ORNELLAS, J. F. Os conteúdos de ensino prescritos nas disciplinas integradoras de alguns cursos de licenciatura em química. 2016. 190f. Tese (Doutorado em Ensino de Ciências) - Universidade de São Paulo, São Paulo, 2016.

PASSOS, C. G. O curso de licenciatura em química da UFRGS: conquistas e desafios frente à reformulação curricular de 2005. Alexandria: Revista de Educação em Ciência e Tecnologia, v. 8, n. 3, p. 81-111, 2015.

PEREIRA, F. A. A integração curricular da educação ambiental na formação inicial de professores: tecendo fios e revelando desafios da pesquisa acadêmica brasileira. 2014. 427f. Tese (Doutorado em Educação) - Universidade Estadual de Campinas, Campinas, 2014.

RAMOS, M. A. S.; FARIA, P. M. M.; FARIA, Á. F. L. Revisão sistemática de literatura: contributo para a inovação na investigação em Ciências da Educação. Revista Diálogo Educacional, v. 14, n. 41, 2014.

RITTER, J.; MALDANER, O. A. CTS na situação de estudo: desenvolvimento de currículo e formação de professores. Práxis e Saber: Revista de Investigación y Pedagogia Maestria en Educacion, v. 6, n. 11, 195-214, 2014. 
ROCHA, P. D. P. Orientações curriculares e políticas públicas para a formação de professores: um estudo sobre o curso de licenciatura em química da UFPel. 2014. 135f. Dissertação (Mestrado em Educação em Ciências) - Universidade Federal do Rio Grande do Sul, Porto Alegre, 2014.

RODRIGUES, A. M. Movimento e contradição: a disciplina de práticas em ensino de física e a formação inicial de professores de física sob uma perspectiva histórico-cultural. 2013. 238f. Tese (Doutorado em Ensino de Ciências) - Universidade de São Paulo, São Paulo, 2013.

ROSA, J. K. L; WEIGERT, C.; SOUZA, A. C. G. Formação docente: reflexões sobre o estágio curricular. Ciência \& Educação, Bauru, v. 18, n. 3, p. 675-688, 2012.

SÁ, C. S. D. S.; SANTOS, W. L. P. Constituição de identidades em um curso de licenciatura em química. Revista Brasileira de Educação, v. 22, n. 69, p. 315-338, 2017. Disponível em: https://doi. org/10.1590/s1413-24782017226917. Acesso em:

7 ago. 2017.

SANTOS, C. A.; VALEIRAS, N. Currículo interdisciplinar para licenciatura em ciências da natureza. Revista Brasileira de Ensino de Física, v. 36, n. 2, 2014.

SCHIMITT, L. A. Educação ambiental e currículo: um olhar sobre a formação inicial de professores de Ciências e Biologia. 2016. 129f. Dissertação (Mestrado em Humanidades) - Pontifícia Universidade Católica do Rio Grande do Sul, Porto Alegre, 2016.

VERDUM, P. L. Formação inicial de professores para a educação básica, no contexto dos IFs: propondo indicadores de qualidade, a partir de um estudo de caso no IFRS. 2015. 281f. Tese (Doutorado em Educação) - Pontifícia Universidade Católica do Rio Grande do Sul, Porto Alegre, 2015.

VIANE, G. M. Construções de relações teoria-prática na formação de professores de ciências e biologia. 2014. 319f. Tese (Doutorado em Educação) - Universidade Federal de Minas Gerais, Belo Horizonte, 2014. 
1 Doutoranda do Programa de Pós-Graduação em Ensino de Ciências e Tecnologia - PPGE. E-mall: dynic@gmail.com

2 Doutor em Educação Científica e Tecnológica pela Universidade Federal de Santa Catarina; Professor do Programa de Pós-Graduação em Ensino de Ciências e Tecnologia da Universidade Tecnológica Federal do Paraná (PPGECTUTFPR). E-mail: awdryfei@gmail.com

\section{(). (1) (-)}

Este artigo é licenciado na modalidade acesso abertosob a Atribuição-Compartilhalgual CC BY-SA

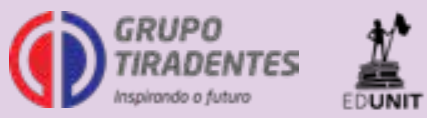

